
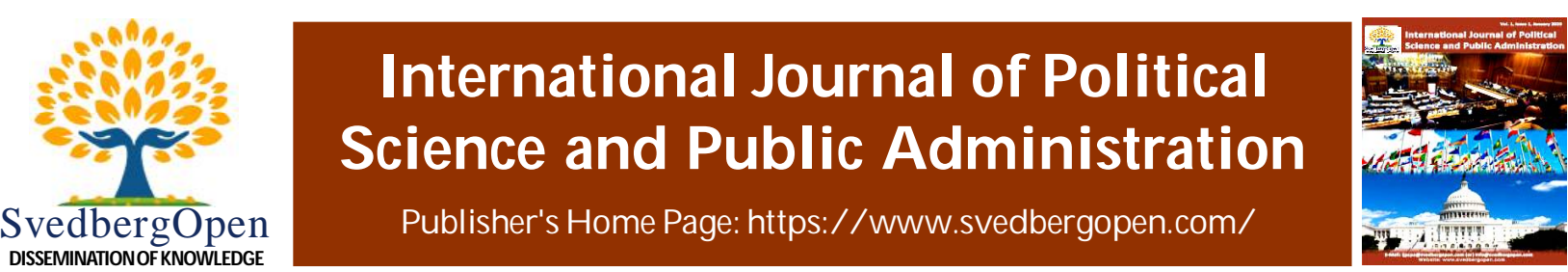

Research Paper

Open A ccess

\title{
Bangladesh Legal Aid and Services Trust (BLAST) in Providing Legal Aid Services to the Oppressed Women: A Study on Sylhet Branch
}

Fatema Khatun ${ }^{1 *}$

${ }^{1}$ Associate Professor, Shahjalal University of Science \& Technology, Sylhet, Bangladesh. E-mail: fatemapa@yahoo.com

\section{Article Info}

Volume 1, Issue 2, September 2021

Received : 05 November 2020

Accepted : 25 July 2021

Published : 05 September 2021

doi: 10.51483/IJPSPA.1.2.2021.13-24

\begin{abstract}
Legal aid is essentially a mechanism that enables the poor and the vulnerable section of the society to enforce their legal rights to access fair and equitable justice in society. Nowadays, legal aid can be justifiably a crying need to ensure social and legal justice in Bangladesh since a large number of the citizens are illiterate and poor which incidentally makes matters worse. Bangladesh Legal Aid and Services Trust (BLAST) which is totally nongovernmental and non-profitable, is one of the leading legal services organizations in Bangladesh. It provides legal aid and support to women, men and children who are living in poverty and facing discrimination. However, this organization faces some challenges while providing services to poor people. The objective of this research is to explore the role of BLAST in providing legal aid services to the vulnerable people and the challenges it faces. This research is both qualitative and quantitative in nature. Data for this research has been collected from both primary (questionnaire and observation) and secondary sources. The study finds that a vast number of people, especially poor and oppressed women, are being benefited by this agency. The study also finds that this organization is suffering from a lack of logistic support and, in some cases, facing political threats.
\end{abstract}

Keywords: Bangladesh Legal Aid and Services Trust (BLAST), Legal aid, Oppressed, Women, Human Rights, Justice

(C) 2021 Fatema Khatun. This is an open access article under the CC BY license (https://creativecommons.org/licenses/by/4.0/), which permits unrestricted use, distribution, and reproduction in any medium, provided you give appropriate credit to the original author(s) and the source, provide a link to the Creative Commons license, and indicate if changes were made.

\section{Introduction}

Women in Bangladesh have been subjected to exploitation and negligence for decades. In Bangladesh oppression of women has become a common scenario. Every day we find news in electronic and print media about the oppression of women which is increasing at an alarming rate. Our country is male-dominated and women have always been kept oppressed by religious fanaticism, superstition, oppression and discrimination. Their merit and labor have not been recognized in domestic lore. Bangladesh is one of the most vulnerable countries in the world where women are living in a very dangerous situation, even though it has a woman prime minister. The major forms of women's oppression include dowry, trafficking, kidnapping, rape, physical torture, acid throwing and sexual harassment. Almost every day, women are victimized by these acts of violence and repression. And domestic violence at the hand of the husband is a very routine practice in Bangladesh. In Bangladesh, there are many laws forth protection of women, for instance, the Suppression of Immoral Traffic Act, 1993, the Family Court Ordinance, the Trafficking in Women and Children Act, 1993,

\footnotetext{
* Corresponding author: Fatema Khatun, University Affiliation: Shahjalal University of Science \& Technology, Sylhet, Bangladesh. E-mail: fatemapa@yahoo.com
}

2788-8983/@ 2021. Fatema Khatun. This is an open access article distributed under the Creative Commons Attribution License, which permits unrestricted use, distribution, and reproduction in any medium, provided the original work is properly cited 
the Dowry Prohibition Act and the Prevention of Women and Child Repression Act, 2000. But, unfortunately, they could not stop the oppression against women totally yet.

In Bangladesh, there are different types of government and on-government agencies which work and deal with women's oppression. Bangladesh Legal Aid and Services Trust (BLAST) is one of them. It provides legal aid, advice and suggestions regarding family, civil, criminal, labor and land law. Its mission is to make the legal system accessible to the poor, marginalized and excluded women, children, and people with disabilities so that their human rights get respected and protected. BLAST aims to bring about a positive change among the poor and disadvantaged people. That is why it provides legal aid to safeguard their fundamental rights through the judicial system and mediation.

BLAST was founded in 1993 as a free legal services organization. It has a Board of Trustees consisting of eminent jurists, lawyers, and former judges of the Bangladesh Supreme Court. Though the organization started working at five offices in 1994, it expanded rapidly. And now it has nineteen unit offices apart from the head office in Dhaka. From the magistrate courts to Supreme Court, BLAST operates everywhere at the frontlines of the legal system. It is the only legal services group which provides advice and assistance regarding criminal, family, civil, land, and constitutional law related matters. Though, in the beginning, BLAST focused on providing legal aid only, it soon expanded its working area to include alternative dispute resolution, public interest litigation, and legislative advocacy. Thus, it provides justice to marginalized and vulnerable people at a wider range. Regarding public interest, BLAST has undertaken significant legal actions on criminal justice, economic and social rights and equality issues. Its most recent work has added litigation regarding extrajudicial killing, women's rights, advice rights, and rights of persons with disabilities.

BLAST, at present working in 19 districts, do perform its functions through supporting advocates at head office and in every sub units, in coordination with its panel advocates all over the country. These advocates put hands to the clients with minimum charges. A group of lawyers who are practicing legal business in the apex court also helps the client to sue litigation and fight in favor of them until the settlement of the litigation. BLAST has a Board of Trustee whose members are prominent judges, advocates and human rights activist. In fact, they lead the organization since they have experiences in human rights related works. BLAST is also getting support from a consultative group including professionals, researchers, advocates and human rights activists. This organization has a deep connection with the Bar Associations across the country. BLAST undertakes awareness program at a regular basis on legal rights for community members in its areas of operation, including family laws, criminal law and land laws. It is also involved in regular coordination meetings with local administration officials, in particular with key actors within the justice system (BLAST, 2005).

\section{Rationale of the Study}

Human being habitually becomes the victim of oppression. But, women become the victim at a greater level because of their gender identity. Almost every women face oppression from their husband and other male members of their own family. And many of these women do suffer throughout their whole life. Today oppression of women is a much-talked phenomenon in third world countries. In Bangladesh, development is getting hampered because of the oppression of women who are a significant part of the workforce here.

Because of the violence facing in society, women often get deprived of their basic rights as human beings. Therefore, this study on oppressed women would raise awareness in society and bring a change in their lives positively. It will contribute to remove the suffocated situation that women unfortunately live in. From this study, one would come to understand the nature of oppression and its present condition in a wider angle since the study would give a close observation. It might create a room for conversation regarding oppression against women and its solution. This study would also lights upon BLAST's works which ranges from removing oppression to improving the situation for women by proving legal aid and services to them.

\section{Objective of the Study}

The broad objective is to find out the role of BLAST in providing legal aid and services to oppressed women. The specific objectives are:

- To examine the services provided by BLAST for the oppressed women.

- To identify the challenges of BLAST in providing their services.

- To put some possible recommendations. 


\section{Research Question}

This study is conducted through some fundamental research based questions:

1. What is the role of BLAST in providing legal aid to oppressed women?

2. What are the challenges faced by BLAST in providing services?

\section{Methodology}

This research is both qualitative and quantitative in its nature. The social survey method has been used for this research. Data has been collected through direct interviews and observations. Primary data has been collected through a structured method of the questionnaire, both close- and open-ended. Around 100 people, receiving legal services from BLAST, from Sylhet city area, were contacted, talked and asked to participate in the questionnaire. The secondary data has been collected from available books, journals, newspapers, BLAST report, website and other online sources. The total population of this study were 200 (they have received the services in 3 months) and the study has selected 132 samples (Krejcie and Morgan's Sample Size with 5.0\% error) by the purposive sampling method.

\section{Literature Review}

BLAST regularly provides legal aid to indigent prisoners, and has, in recent years, been doing so through paralegals in particular districts through a pilot project, Improvement of Real Situation of Overcrowding in Prisons (IRSOP) in collaboration with the Ministry of Home Affairs and the Ministry of Law. Over the last years, BLAST researched alternatives to imprisonment in Bangladesh and in doing so, it got support from PRI. It is hoped that, at the present time, a review of this research with experts in the field will assist us to assess the laws on probation, and see how far the law is being implemented, what the gaps are and how we can begin to address these or advocate for relevant changes in law, policy and practice (Hossain, 2014).

A judicial dialogue was conducted to address some of the identified challenges, gaps and limits of the law, as well as procedural or practical constraints which deny women the access to justice in the family Courts. The challenges women faces in accessing justice are manifold: legal, procedural, socioeconomic, cultural as well as political. The legal framework for women's economic rights is inadequate, concerning the issues of a right to matrimonial property, dower, and maintenance. Besides, to get justice through the Family courts, women also go through procedural obstacles. Socioeconomic and cultural dynamics also influences on women in securing legal remedies for family disputes, as do the politics of gender and religion (BLAST, 2013).

Through research and discussions with lawyers and doctors, BLAST, a national legal aid and services organization, has identified several of the main barriers to have access to justice.

A key barrier identified is Section 155(4) of the Evidence ACT 1872 (BLAST, 2006), relating to character evidence in rape cases. This provision states that "when a man is prosecuted for rape or an attempt to ravish, it may be shown that the prosecution was generally immoral." The introduction of character evidence, which attempts to show that a person was 'immoral', is humiliating and degrading for the survivor. It also actively deters survivors from reporting rape. It results in a legal and moral anomaly where a woman who is alleging a right's violation, is compelled to prove her 'good character' in order to secure justice (Datta, 2015).

BLAST welcomes the calls by the Law Commission of Bangladesh and the Hon'ble Chief Justice of Bangladesh to repeal the controversial provisions of the 143-year-old Evidence Act. These calls triggered a momentum within the legal profession and civil society, calling for a change to the law. Participants at a conference on "Use of Character Evidence in Rape Cases in Bangladesh: Section 155 (4) Evidence Act, 1872” which BLAST held in 2014, urged repeal of this provision to protect women's rights and ensure their right of access to justice. The same recommendation was included in BLAST's research on a comparative analysis of the laws on the use of character evidence in rape trials, in seven jurisdictions including Canada, India, Pakistan, South Africa, Singapore, UK and the USA with a view to identifying best practices for law and policy reform (Press Released, BLAST, 2015).

To protect the interest of workers, BLAST filed a petition before the Chamber Judge of the Appellate Division seeking leave to appeal against the High Court's judgment dated 18.06.2013 holding that workers could not make an application under Section 307, without meeting several prior conditions. On behalf of BLAST, it was argued that Section 
307 of the Act is an independent, separate and distinct provision, providing an effective remedy to workers who are denied their dues wrongfully by employers (Press Released, BLAST, 2013).

The Supreme Court ruled that the offenders could be awarded capital punishment or life term for killing after rape, scrapping the provision of only a death sentence for the offence under the Women and Children Repression Prevention (Special) Act, 1995 (The Daily Sun, 2015). Following a writ petition, the HC on March 2, 2010, declared Section 6(2) of the 1995 law illegal and unconstitutional, saying that the death penalty could not be the only punishment for any crime as per the constitutional provision. The writ petition was filed with the HC jointly by Bangladesh Legal Aid and Services Trust (BLAST) (The Daily Star, 2015).

Knowledge Gap: The available study materials discussed the rights of oppressed women in Bangladesh along with the sentences of rape and other gender based crimes. However, the voluntary services that are provided to those women by some philanthropic organization of Bangladesh are remained untouched to some extent. The present study tries find out the role of a non-governmental voluntary organization named BLAST to the oppressed women in Sylhet. Besides, this study will explore the challenges and limitations of BLAST when they are providing service to the poor oppressed women.

\section{Data Presentation and Analysis}

Data analysis is the most important part of social research since it helps to come to a decision about the researched issue. Proper data analysis presents a clear picture of the real situation. All the obtained data of this report, collected by questionnaire, have been explained in this part. And these data have been collected from face to face interview and some primary sources as well.

\subsection{Familiarity with the Services of BLAST}

This Pie chart shows that $80 \%$ of the respondents are familiar with the services of BLAST while $20 \%$ are not.

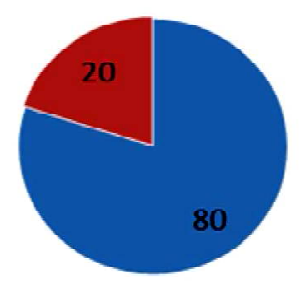

\subsection{Service Received from BLAST}

As the table says, among 100 respondents, 90 received services from BLAST and the remaining 10 did not. And it means that the most of the surveyed ones are the beneficiary of BLAST's service.

\begin{tabular}{|l|c|c|}
\hline Responses & Number of Respondents & Percentage (\%) \\
\hline Yes & 119 & 90 \\
\hline No & 13 & 10 \\
\hline Total & $\mathbf{1 3 2}$ & $\mathbf{1 0 0}$ \\
\hline
\end{tabular}

\subsection{Getting Service in Proper Time}

When the question whether they received service from BLAST in proper time or not, was asked to the participants, $70 \%$ of them answered positively and 30\% negatively. In the case of not getting service in proper time, respondents, pointing out many of their shortcomings, say that BLAST does not have enough efficient personnel to give service and attention to the recipients. 


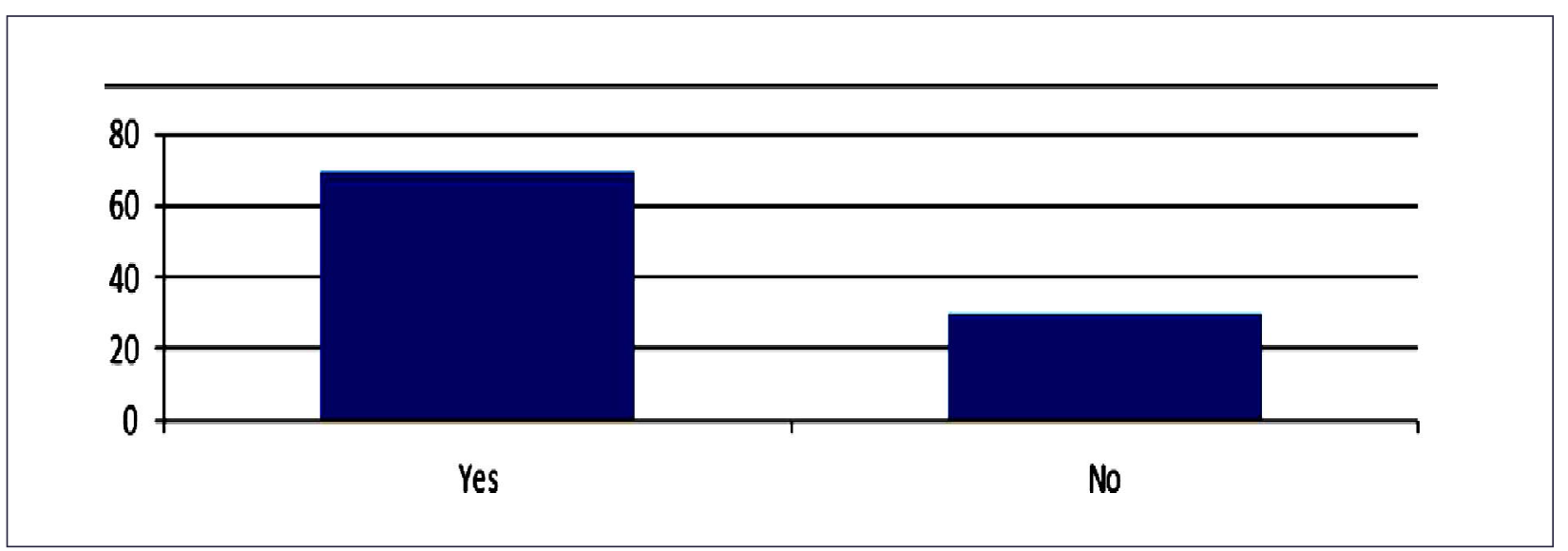

\subsection{Condition After Receiving the Service}

$60 \%$ of the respondents, who took legal service from BLAST, said that they had been living happily after getting service from BLAST. 23\% said their lives had become better than the time before BLAST's help. And the remaining $17 \%$ conformed that even after getting assistance from BLAST, their lives remained the same as far as obstacles and oppressions are concerned.

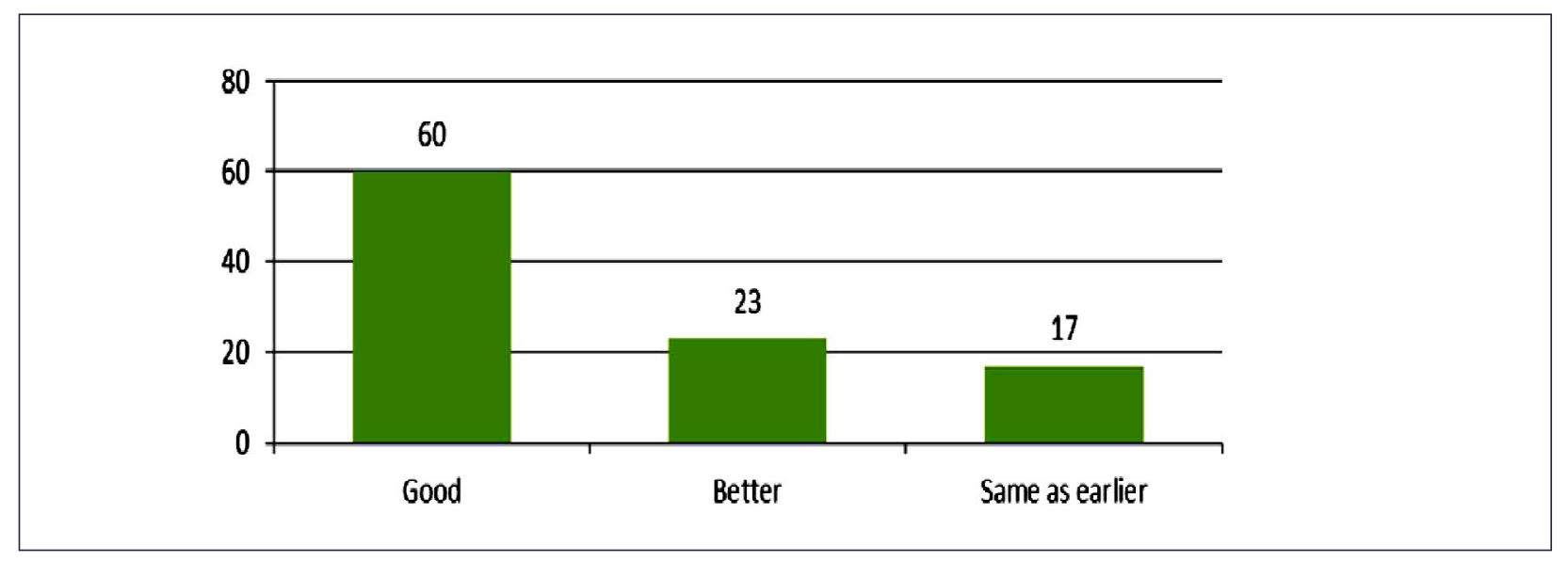

\subsection{Receiving Legal Aid from BLAST}

Figure below indicates that the percentage of receiving legal aid (60\%) from BLAST is higher than that of not receiving it (40\%).

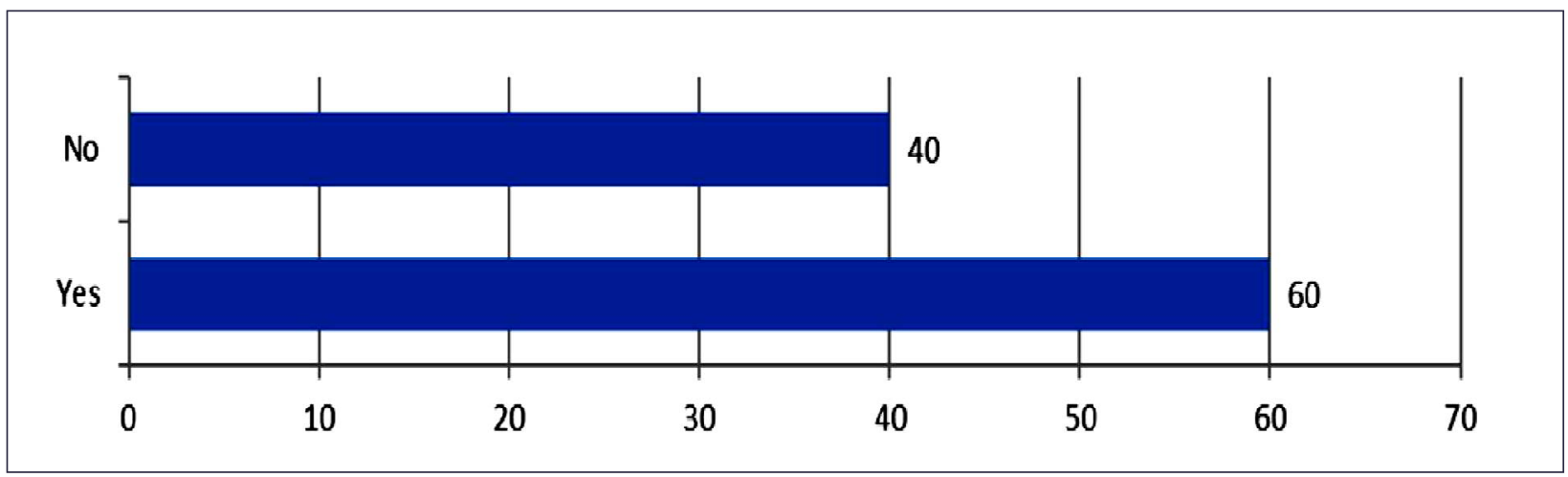

\subsection{Interest Taking by BLAST}

At this question whether BLAST has ever taken interest from its service recipients, all the respondents answered negatively which means BLAST does not charge for the service and aid they give to the vulnerable section of the society. 


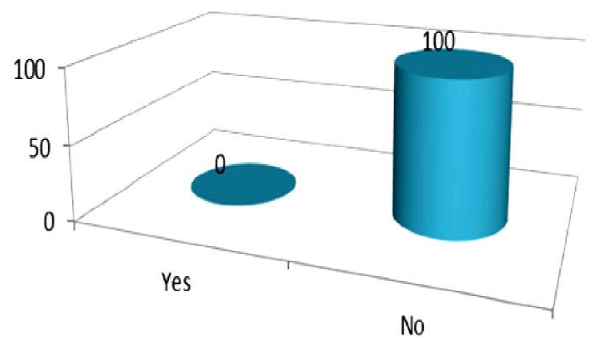

\subsection{Sufficiency of Efficient Workers in the Organization}

When 50\% of the respondents think that BLAST does not have sufficiency of efficient workers, it means they are not very positive about the availability of skilled workers there. This bar graph tells that, of the other half of respondents, $20 \%$ thinks BLAST has enough skilled workers and the remaining $30 \%$ are unaware of this.

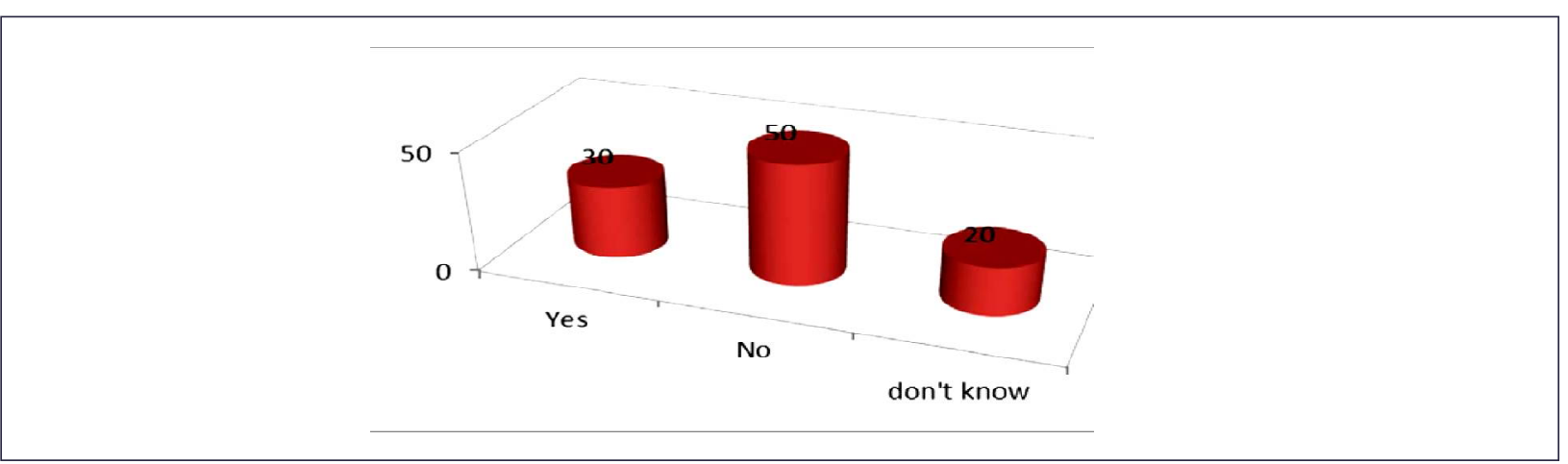

\subsection{Maintaining Confidentiality While Giving Service}

Regarding the issue of keeping information confidential, $43 \%$ the participants said yes, they do maintain it, while $20 \%$ said no to the question. And the remaining $37 \%$ states that BLAST does that partially.

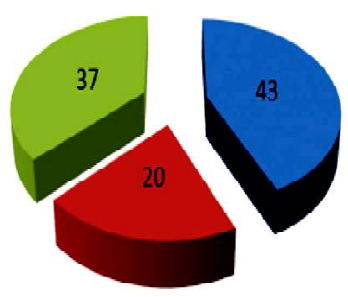

- Yes

No

Partially

\subsection{Efficiency of Personnel in Providing Services}

Being asked about the efficiency level of the personnel of BLAST in providing service, $80 \%$ of the respondents said that they are efficient; $15 \%$ of the respondents said they are not efficient; and the remaining 5\% said they are partially efficient.

\begin{tabular}{|l|c|c|}
\hline Responses & Number of respondents & Percentages (\%) \\
\hline Yes & 106 & 80 \\
\hline No & 20 & 15 \\
\hline Partial & 6 & 5 \\
\hline Total & $\mathbf{1 3 2}$ & $\mathbf{1 0 0}$ \\
\hline
\end{tabular}




\subsection{Satisfaction About BLAST}

This bar graph says that $77 \%$ of the respondents of the survey are satisfied with BLAST, be it just satisfied (60\%) or highly satisfied (17\%) and the other $23 \%$ are not satisfied.

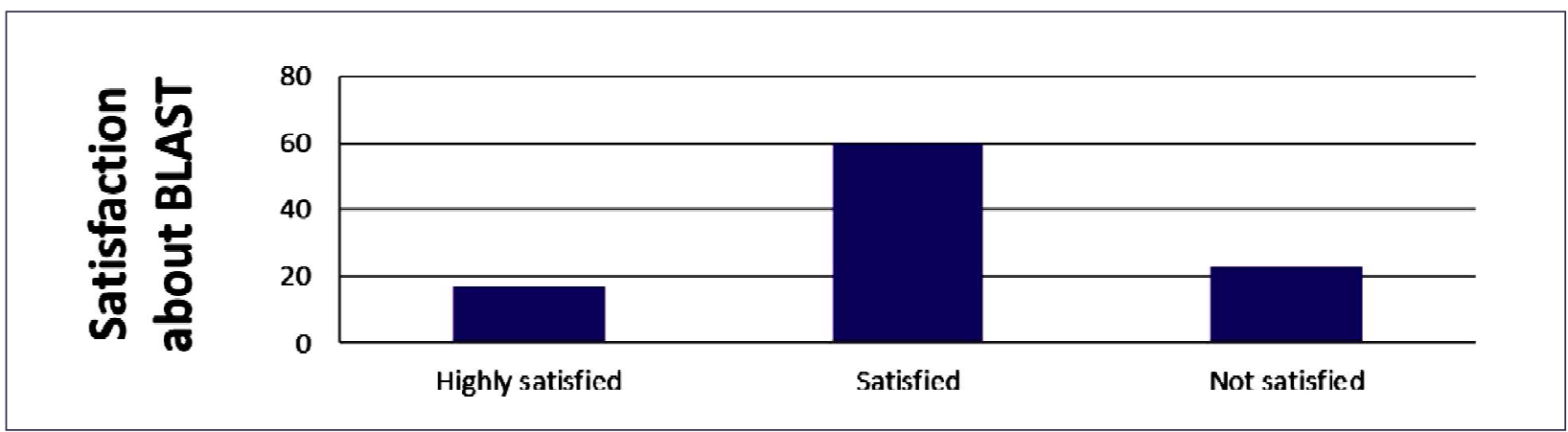

\subsection{Facing Problems While Receiving the Service}

This table shows that, during receiving service, $83 \%$ of the respondents did not face any problem, $10 \%$ faced some problems and $7 \%$ gave no comment on this question. Some of the respondents further added that they were just avoided by the personnel of the BLAST.

\begin{tabular}{|l|c|c|}
\hline Responses & Number of Respondents & Percentages (\%) \\
\hline Yes & 14 & 10 \\
\hline No & 110 & 73 \\
\hline No comment & 8 & $\mathbf{1 0 0}$ \\
\hline Total & $\mathbf{1 3 2}$ & 7 \\
\hline
\end{tabular}

\subsection{Responses of Service Provider: Working Independently Without any Influence of Government}

When the service providers of BLAST are asked whether government tries to influence their works, $70 \%$ says that they can work independently without any pressure from government. But $10 \%$ says that government does interfere while the remaining $20 \%$ declines to answer.

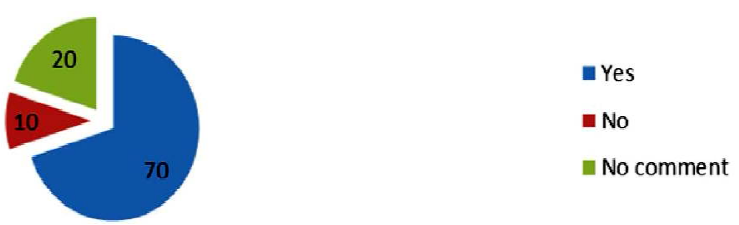

\subsection{Facing Influences and Threats While Giving Services}

This pie chart shows the scenario of facing local pressure by the workers of BLAST while giving services, $80 \%$ said that they face local pressure sometimes while $10 \%$ conformed of facing local threats and interferences in rendering their service to their clients. The remaining $10 \%$ said, there is no such pressure at all. So, it can be inferred from the responses

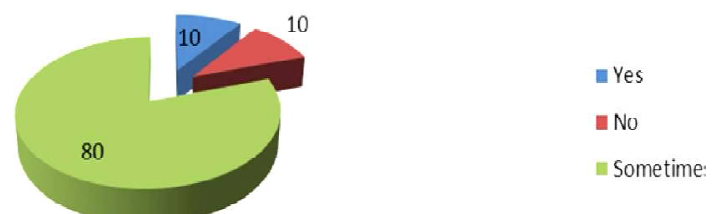


that the powerful ones from the clients' locality try to influence the cases to solve them as per their will. When the service providers face such issues, they seek help from judicial systems.

\subsection{Facing Financial Crisis in Providing Service}

At the question regarding financial crisis faced by BLAST, 70\% of the respondents said that they face financial crisis while giving service to the clients; $10 \%$ said that they don't face any financial crisis; and $20 \%$ of the respondents refused to comment on this question. Those who answered positively, talk about not having enough donors. As a result, it affects their service to some extent.

\begin{tabular}{|l|c|c|}
\hline Responses & Number of Respondents & Percentages (\%) \\
\hline Yes & 92 & 70 \\
\hline No & 13 & 10 \\
\hline No comment & 27 & 20 \\
\hline Total & $\mathbf{1 3 2}$ & $\mathbf{1 0 0}$ \\
\hline
\end{tabular}

\subsection{Maintenance of Confidentiality of Clients in Providing Service}

About maintaining the confidentiality of the clients, $50 \%$ of the respondents said that the confidentiality of the clients are highly maintained; $40 \%$ of the respondents said that it is partially maintained; and the remaining $10 \%$ said that it is not maintained. While answering, they explained that while giving legal aid and running cases, it is not always possible to keep everything confidential.

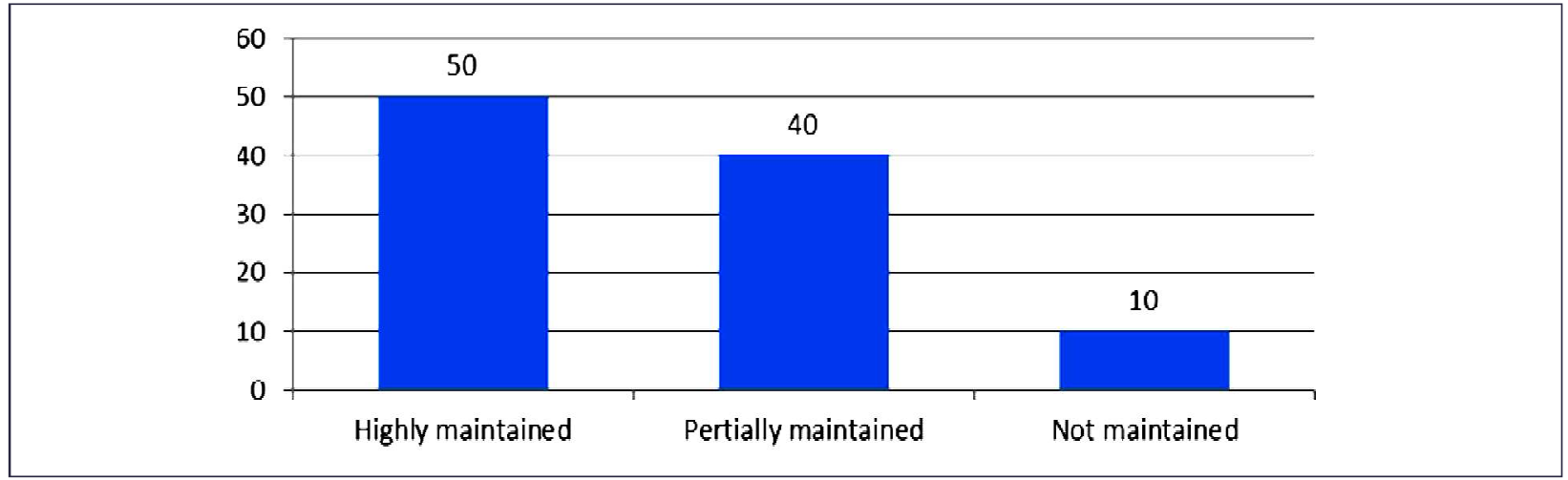

\subsection{Government's Cooperation with BLAST}

This pie chart shows that $60 \%$ of the respondents consider the government as a helpful one for BLAST while $30 \%$ do not think so. And the remaining $10 \%$ think, the government is partially cooperative.

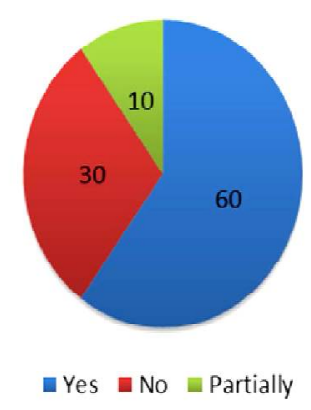

\subsection{Maintenance of Transparency While Providing Service}

This bar chart says $70 \%$ of the respondents maintained transparency highly; $20 \%$ of the respondents did maintain it partially; and the remaining $10 \%$ said that they did not maintain transparency at all. 


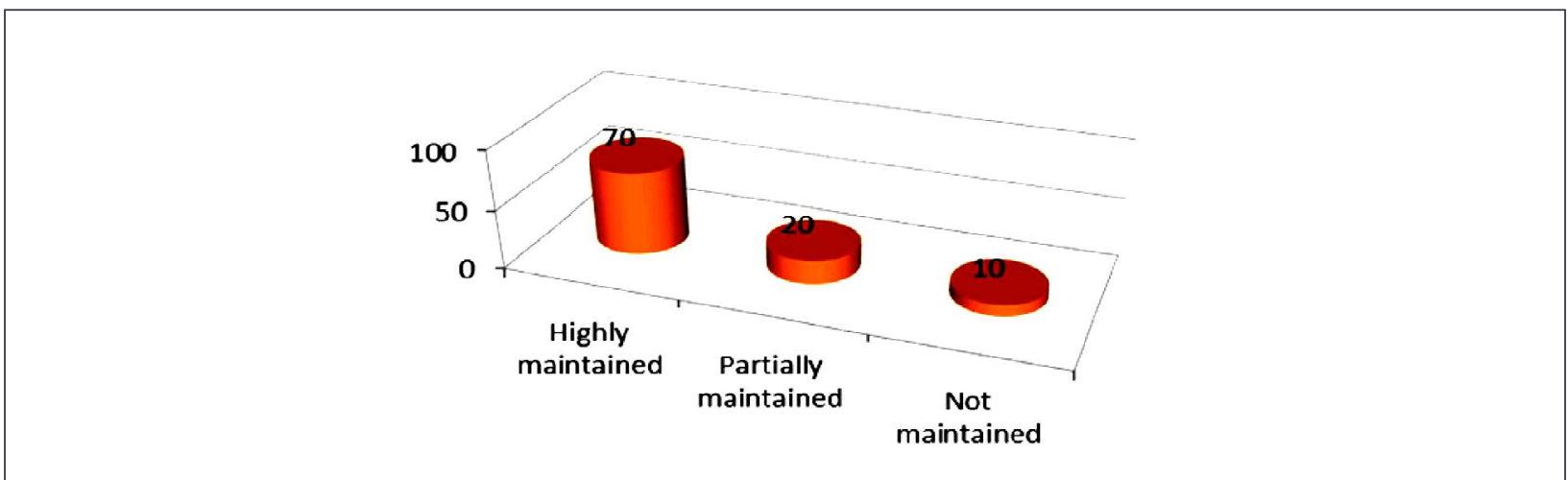

\subsection{Sufficiency of Efficient Personnel in BLAST}

$60 \%$ of the respondents from BLAST think that the organization has enough efficient personnel to provide a standard service. But the other 30\% do not think so. Rather, they opine that BLAST lacks skilled employees. And, there are the other $10 \%$ who refuse to answer this question.

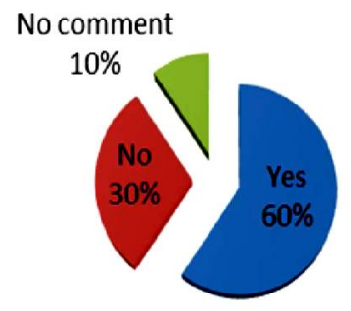

\section{Findings of the Study}

After analyzing the data, we have got to know about several aspects of BLAST's work very specifically. Some of them are positives ones while the other negative.

\section{Positive Aspects}

- BLAST helps the people in problem based on their felt needs. A vast number of people especially poor and oppressed women are being benefited by this agency. And these poor and oppressed women usually can not turn to anybody for legal aid support since they do not have the financial solvency to pay for that. And for them, BLAST is the best they could expect and have since it brings legal help to them without charging any fees.

- Most of the time BLAST's mediation process solves the client's problem. This mediation process is much more fruitful than the litigation process in problem-solving. It saves time and money. When it becomes impossible to solve the problem through mediation only then the case gets forwarded and referred to the court. BLAST fills cases in favor of the clients and operates without taking any cost from them. Besides carrying litigation cost, BLAST also provides transportation cost of the clients.

- One of the major achievements of BLAST is to collect dower money and child maintenance from the opposite party after the divorce which is a difficult task for women, particularly when they are so powerless. When it is settled to provide dower money by the opposite party, sometimes he pays it by one instalment. But in most cases, it is not possible for the party to pay it by one instalment, so he pays it through few instalments. BLAST collects this money from him and provides them to the petitioner.

- Many women who are tortured both physically and mentally in their conjugal lives, can ask for help from BLAST. Thus, they could return to their normal happy life again, getting help from the organization. With the help and guidance from BLAST, they get the chance to have a future with hope and aspiration.

- BLAST takes active initiative to stop violence against women. And that is why most of the helping areas of BLAST are related to protecting women from dowry and second marriage, criminal cases (rape, murder, 
drug etc.), crime against women, land cases and labor matters. So, it is quite understandable that BLAST plays a significant role in empowering women.

- BLAST has its strong monitoring and evaluating cell that monitors and evaluates all the units across the country once a year. So, the staffs remain alert to do their respective duties properly. Thus, BLAST tries to ensure an effective service all over the places it works.

- The Petitioner getting benefited every year is the most worthy task of the agency and it is purpose the organization, mainly, works for.

- Dower, maintenance, custody of the child, protecting women from dowry and crime against are the major areas where BLAST offers help to women.

\section{Negative Aspects}

- $\quad$ BLAST is not very widely known across the country. In fact, among vulnerable section of the country, it is not a widely familiar name. It takes little initiative to let people, particularly that section they mainly work for, inform about its services. Once in a year, they publish an annual report which is not enough.

- BLAST takes little steps to check on its beneficiaries' condition as far as their problems are concern, once they go back after getting the service. Yes, most of their clients get their problem solved and their lives get better. But, even then, BLAST could do a bit monitoring on them rather than being totally detach from them.

- Most of BLAST's task is office centered, rather than being field centered. For this reason, they cannot monitor their client's condition properly. And, maybe, because of that, many of their clients' problems always remained unknown.

- Most of the clients do not know about the mitigation process. As a result, when conducting follow up, they cannot answer properly. Actually, the poor people don't know much about BLAST's mediation process.

- BLAST handles many cases through mitigation process since it does not have specialists to study their clients' problems minutely. As a result, sometimes, they suggest their clients to solve their problems by themselves.

- The agency does not have any monitoring system so that they could observe and guide their clients in utilizing their dower money in a productive manner.

\section{Limitation of BLAST}

- The agency is suffering from necessary personnel. For this reason, they can't monitor their clients properly at the field level. They do not have workers to motivate the parties, especially when the parties don't attend the mediation.

- The space for mediation is very congested and the sitting arrangement is not favorable to prosecute hearing in an effective way. In most cases, it is seen that the other party of the mediation sits in the same room. So, the clients feel uncomfortable sharing their problems before them

- There are no specialist personnel in BLAST to study the person who is in problem, deeply and that is why, they, sometimes, motivate the help seekers in order to solve their problems by themselves.

- In case of the long absence of the opposite party, BLAST can do a little to make the opposite party be present.

- Very few people of Bangladesh know that BLAST is working very efficiently to ensure human rights, especially the establishment of women rights and justice. Most of the oppressed women are not well informed about their unit offices because of the lack of information regarding that.

- Some of the staffs of BLAST are not well trained; they need to be trained properly since they are dealing cases related to human psychology.

- The agency does not have any monitoring system to keep eyes on whether their beneficiaries utilize the dower money in the productive sector or not. 


\section{Recommendations}

During time of collecting data, we observed some limitations of BLAST's agency. So, from that observation, some recommendations to accelerate the performance of this agency are given below:

- First of all, training is essential for the staffs of the agency. If they get proper training, then the mediation process will be more fruitful.

- The agency should have a good evaluating and monitoring system so that they may know how the clients lead their life after getting services from the agency.

- The follow-up system of the agency is not satisfactory. To know how much their lives get better after receiving services, follow up is very essential.

- It is very much essential to ensure motivational activities for the client and the opposite party. If they get motivated properly, they must attend to the arbitration process. As a result, both parties would get a chance to solve their respective problems.

- The agency can set up a shelter house for the oppressed women so that they can stay there until their problem gets solved. Sheltering these women throughout the whole legal aid process is necessary since they, sometimes, gets threats not to be present in hearing. And they feel insecure.

- The agency can start a rehabilitation program for oppressed women so that they can be self-reliant and self-dependent.

- $\quad$ BLAST should have specific rooms for mediation to make the clients feel comfortable in sharing their opinions and views.

- If the opposite party is not present in the three mediation meetings, then the case is sent to the court. This may increase resentment among the parties. So, the agency should try more to contact and convince the opposite parties to be present in the mediation meeting.

- BLAST should try to raise awareness among people through field meeting, seminar, symposium, workshop, etc. about their rights and BLAST's aid in achieving that. Besides, it can keep strong communication with mass media (such as print and electronic media) for expanding its services.

\section{Conclusion}

BLAST provides legal advice and representation at all levels of the justice system with an emphasis on providing services to those living in poverty and discrimination. Any people can get legal support and help from this agency. BLAST works to put an end to all sorts of violence against women. Most of BLAST's helping areas touch matters, like- protecting women from dowry and second marriage, criminal case (rape, murder, drug etc.) crime against women, land cases and labor matters. So, its range of services plays a significant role in empowering women. Legal services, including mediation, litigation and legal rights training are provided by BLAST to the oppressed women. At present, oppression of women in society is quite massive. In this situation, we have seen that BLAST is playing a vital role to help the oppressed in getting support and justice. Thus it is contributing to eradicate this sort of violence from society gradually. And it does all these without charging any money from them. Nothing could be more applauding other than this.

\section{References}

Bangladesh Legal Aid and Services Trust (BLAST). (2005). Annual report 2004-2005. Dhaka: Bangladesh Legal Aid and Services Trust (BLAST).

Bangladesh Legal Aid and Services Trust (BLAST). (2006). Strategic policy and future direction of BLAST, Dhaka: Bangladesh Legal Aid and Services Trust (BLAST).

Bangladesh Legal Aid and Services Trust (BLAST). (2013). Gender, knowledge, networking and human rights intervention in Bangladesh (GKNHRIB): Concept note on extension of GKNHRIB, BLAST. Dhaka: Bangladesh Legal Aid and Services Trust (BLAST).

Bangladesh Legal Aid and Services Trust (BLAST). (2015). Public interest litigation and advocacy, BLAST: Impact Study. Dhaka: Bangladesh Legal Aid and Services Trust (BLAST). 
Datta, I. (2015). A "rape shield" law for Bangladesh. The Daily Star. Retrieved from https://www.thedailystar.net/op-ed/ $\%$ E2\%80\%9Crape-shield\%E2\%80\%9D-law-bangladesh-97516

Hossain, Sara. (2014). Brief Description of Organization, [Online]. Available From: http://iid.org.bd/team/sara-hossain/ [Accessed in: 23 June,2015]

The Daily Star. (2015). Bangladesh Supreme Court scraps death penalty provision of a law for murder after rape. Retrieved from https://www.thedailystar.net/backpage/death-penalty-95-law-scrapped-80686

Cite this article as: Fatema Khatun (2021). Bangladesh Legal Aid and Services Trust (BLA ST) in Providing Legal Aid Services to the Oppressed Women: A Study on Sylhet Branch. International J ournal of P olitical Scienceand Public A dministration, 1(2), 13-24. doi: 10.51483/ IJPSPA.1.2.2021.13-24. 